\title{
Variable Denticity in Carboxylate Binding to the Uranyl Coordination Complexes
}

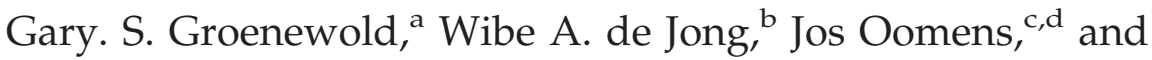 \\ Michael J. Van Stipdonk ${ }^{\mathrm{e}}$ \\ ${ }^{a}$ Idaho National Laboratory, Idaho Falls, Idaho, USA \\ ${ }^{\mathrm{b}}$ Pacific Northwest National Laboratory, Richland, Washington, USA \\ ${ }^{\mathrm{c}}$ FOM Instituut voor Plasmafysica, Nieuwegein, The Netherlands \\ d University of Amsterdam, Amsterdam, The Netherlands \\ e Department of Chemistry, Wichita State University, Wichita, Kansas, USA
}

$\overline{\text { Tris-carboxylate complexes of uranyl }\left[\mathrm{UO}_{2}\right]^{2+} \text { with acetate and benzoate were generated using }}$ electrospray ionization mass spectrometry, and then isolated in a Fourier transform ion cyclotron resonance mass spectrometer. Wavelength-selective infrared multiple photon dissociation (IRMPD) of the tris-acetato uranyl anion resulted in a redox elimination of an acetate radical, which was used to generate an IR spectrum that consisted of six prominent absorption bands. These were interpreted with the aid of density functional theory calculations in terms of symmetric and antisymmetric $-\mathrm{CO}_{2}$ stretches of the monodentate and bidentate acetate, $\mathrm{CH}_{3}$ bending and umbrella vibrations, and a uranyl $\mathrm{O}-\mathrm{U}-\mathrm{O}$ asymmetric stretch. The comparison of the calculated and measured IR spectra indicated that the predominant conformer of the tris-acetate complex contained two acetate ligands bound in a bidentate fashion, while the third acetate was monodentate. In similar fashion, the tris-benzoate uranyl anion was formed and photodissociated by loss of a benzoate radical, enabling measurement of the infrared spectrum that was in close agreement with that calculated for a structure containing one monodentate and two bidentate benzoate ligands. (J Am Soc Mass Spectrom 2010, 21, 719-727) (C 2010 Published by Elsevier Inc. on behalf of American Society for Mass Spectrometry

$\mathrm{T}$ The structure and reactivity of uranyl $\left(\mathrm{UO}_{2}^{2+}\right)$ carboxylate complexes have been subjects of ongoing experimental and theoretical investigations because these species influence uranium disposition in industrial processes, in the environment, and in biological systems. Compounds like oxalic acid and ethylenediamine tetraacetic acid are used to coordinate uranium in industrial settings, while carboxylate functional groups in humates and siderophores coordinate with uranium in natural environments. The widespread importance of the carboxylate functional group has spurred detailed binding investigations that have frequently utilized acetate and benzoate as model compounds for carboxylates found in more complicated systems.

The mode of acetate coordination is highly dependent on the chemical environment of the coordination complex. The antisymmetric $\left(\nu_{\text {asym }}\right)$ and symmetric $\left(\nu_{\text {sym }}\right) \mathrm{O}-\mathrm{C}-\mathrm{O}$ vibrations, together with the difference $\Delta \nu_{\text {asym-sym }}$, have been shown to be indicative of the strength of coordination, and the mode of binding, which can be monodentate or bidentate. In aqueous solution, the majority of values reported for these

Address reprint requests to Dr. G. S. Groenewold, Department of Chemistry, Idaho National Laboratory, P.O. Bx 1625, MS 2208, Idaho Falls, ID 83415-2208, USA. E-mail: gary.groenewold@inl.gov frequencies were indicative of bidentate acetate coordination, with $\nu_{\text {asym }}$ ranging from 1527 to $1538 \mathrm{~cm}^{-1}, \nu_{\text {sym }}$ from 1467 to $1466 \mathrm{~cm}^{-1}$, and $\Delta \nu_{\text {asym-sym }}$ from 72 to 60 $\mathrm{cm}^{-1}[1-4]$. However, additional $\nu_{\text {asym }}$ and $\nu_{\text {sym }}$ vibrational frequencies have been measured that range from 1595 to 1603 and 1389 to $1390 \mathrm{~cm}^{-1}\left(\Delta \nu_{\text {asym-sym }}=\right.$ $\left.206-213 \mathrm{~cm}^{-1}\right)$ and are indicative acetate coordinated in a monodentate [1, 2], or "pseudobridging" coordination, in which one $\mathrm{O}$ atom of OAc was coordinated to the $\mathrm{U}$ metal center, while the second was hydrogen bound to a geminal $\mathrm{H}_{2} \mathrm{O}$ [4]. For the $\mathrm{UO}_{2}(\mathrm{OAc})_{3}^{-}$in an organic solvent $\left(\mathrm{CH}_{2} \mathrm{Cl}_{2}\right)$, the $\nu_{\text {asym }}$ and $\nu_{\text {sym }}$ values were similar to those in aqueous media, at 1548 and $1461 \mathrm{~cm}^{-1}$, respectively, and $\Delta \nu_{\text {asym-sym }}=87 \mathrm{~cm}^{-1}$, indicative of bidentate coordination [2]. Bidentate coordination is also seen in the IR spectra of crystalline uranyl acetate compounds: the $\nu_{\text {asym }}$ and $\nu_{\text {sym }}$ values for $\mathrm{Na}\left[\mathrm{UO}_{2}(\mathrm{OAc})_{3}\right]$ were 1537 and $1472 \mathrm{~cm}^{-1}\left(\Delta \nu_{\text {asym-sym }}\right.$ value of $\left.65 \mathrm{~cm}^{-1}\right)$, [5] and in this salt the binding mode was confirmed by the crystal structure [6]. The interpretation of the IR spectrum of crystalline $\mathrm{UO}_{2}(\mathrm{OAc})_{2}-$ $2 \mathrm{H}_{2} \mathrm{O}$ also indicates bidentate coordination $\left(\nu_{\text {asym }}\right.$ and $\nu_{\text {sym }}$ at 1513 and $1477 \mathrm{~cm}^{-1}\left(\Delta \nu_{\text {asym-sym }}\right.$ of $\left.\left.36 \mathrm{~cm}^{-1}\right)\right)$ [2]. The crystal structure revealed that half of the acetate was coordinated in a bidentate form, and the rest of the acetate bridges between adjacent uranyl molecules [7], which suggests that the carboxylate frequencies for a
(C) 2010 Published by Elsevier Inc. on behalf of American Society for Mass Spectrometry. 1044-0305/10/\$32.00

doi:10.1016/j.jasms.2010.01.021
Published online January 28, 2010 Received November 20, 2009 Revised January 15, 2010 Accepted January 16, 2010 
bridging monodentate differ from monodentate ligands found in solution-phase complexes. These prior studies of the carboxylate stretches show the utility of IR for evaluating coordination mode, and also show that the chemical environment of the uranyl acetate exerts a strong influence on the nature of acetate coordination.

Changes in the acetate $\mathrm{O}-\mathrm{C}-\mathrm{O}$ frequencies are mirrored by those seen in the uranyl moiety, which exhibits a strong, sharp asymmetric O-U-O vibration $\left(\nu_{3}\right)$ between 900 and $1000 \mathrm{~cm}^{-1}$. The $\nu_{3}$ frequency inversely trends with ligand binding strength, viz., the stronger the ligand binding to the uranyl metal center, the lower the $\nu_{3}$ value. The uranyl moiety also displays a symmetric stretching mode $\left(\nu_{1}\right)$, but because of the pronounced tendency of this molecule to be linear, the $\nu_{1}$ vibration is not usually seen in the IR spectrum. On account of the chemically diagnostic value of the uranyl frequencies, measurements have been widely reported. Solution phase measurements tend to produce values between 919 and $930 \mathrm{~cm}^{-1}$, with higher values corresponding to complexes containing a monodentate acetate, while the lower values contained only bidentate acetates [1-4]. The tetrabutylammonium $\left[\mathrm{UO}_{2}(\mathrm{OAc})_{3}\right]^{-}$ salt dissolved in methylene chloride gave a slightly lower value at $922 \mathrm{~cm}^{-1}$ [2]. While the variations in the $\nu_{3}$ stretch tend to be small, they also indicate the presence of multiple isomeric complexes in solution, a conclusion consistent with the findings of NguyenTrung et al., who studied the symmetric uranyl stretch $\left(\nu_{1}\right)$ for the uranyl-acetate system. The spectra indicated the presence of species having bidentate and monodentate acetate ligands, and that the relative concentrations of these species varied depending on the total solution concentration and $\mathrm{pH}$ [8]. In comparing coordination in solution with the crystalline phase, the spectrum of crystalline $\mathrm{NaUO}_{2}(\mathrm{OAc})_{3}$ produced a $\nu_{3}$ value of $931 \mathrm{~cm}^{-1}$ [2], suggesting slightly weaker binding.

As in the case of acetate, infrared spectroscopy of metal coordinated benzoate is consistent with bidentate coordination, with $\mathrm{C}_{6} \mathrm{H}_{5} \mathrm{CO}_{2}^{-}$carboxylate $\nu_{\text {asym }}$ and $\nu_{\text {sym }}$ values that range from 1552 to 1554 , and 1395 to 1413 $\mathrm{cm}^{-1}$, respectively, and $\Delta \nu_{\text {asym-sym }}$ values ranging from 139 to $158 \mathrm{~cm}^{-1}$ [9-13]. A sharp peak at $1599 \mathrm{~cm}^{-1}$ is attributed to aromatic $\mathrm{C}-\mathrm{C}$ stretching [10].

Uranyl acetate complexes in which the ligands were both monodentate and bidentate have been observed using X-ray absorption spectroscopy [14]. Extended X-ray absorption fine structure spectroscopy (EXAFS) showed that monodentate and bidentate coordination in solution can be differentiated on the basis of differences in the $\mathrm{U}-\mathrm{O}_{\text {axial }}$ bond distances, and that the coordination mode was influenced by the solution chemistry and complex stoichiometry. Bidentate coordination is favored in mono-acetato complexes [15], low $\mathrm{OAc} / \mathrm{UO}_{2}$ ratios, and low $\mathrm{pH}$ [16]. For bis-acetato complexes, EXAFS has also indicated bidentate coordination [17], however not all studies have reached definitive conclusion regarding these complexes [15]. Mono- dentate complexes tend to be formed at higher $\mathrm{pH}$ values and higher OAc concentrations [16]. Significantly, in solution multiple complexes are always present, which complicates interpretation.

In a more complicated biological molecule, monodentate coordinated carboxylate can be favored as indicated by EXAFS and IR studies of uranyl-humic acid complexes [18] that were compared with results from tris-acetato and tris-benzoato solids. Comparisons of the $\mathrm{U}-\mathrm{O}_{\text {equatorial }}$ distances and the $\Delta \nu_{\text {asym-sym }}$ splitting were interpreted in terms of monodentate coordination in the humic acid complexes, bidentate coordination in solid $\mathrm{Na}\left[\mathrm{UO}_{2}(\mathrm{OAc})_{3}\right]$, and benzoate coordination that is bridging monodentate in solid $\left[\mathrm{UO}_{2}(\mathrm{OBz})_{2}\right]$; in the latter, one of the carboxylate $\mathrm{O}$ atoms is bound to a $\mathrm{U}$ atom, while the other is bound to an adjacent $U$ atom in the crystal structure [16]. The bidentate coordination concluded for $\mathrm{Na}\left[\mathrm{UO}_{2}(\mathrm{OAc})_{3}\right]$ agreed with the previously measured X-ray crystal structure [6, 19]. Interestingly, EXAFS of crystalline $\left[\mathrm{UO}_{2}(\mathrm{OAc})_{2} \bullet 2 \mathrm{H}_{2} \mathrm{O}\right]$ showed both monodentate and bidentate coordination: one acetate is bidentate, while the other two are bridging monodentate $[7,15]$.

Uranyl carboxylates have also been the subject of several computational studies that have produced frequency trends for uranyl $\nu_{3}$ values that were consistent with those expected based on ligand nucleophilicities. Ray and coworkers used DFT to study uranyl complexed with benzoate and four $\mathrm{H}_{2} \mathrm{O}$ ligands [20], and showed that the monodentate complexes were predicted to have energies slightly lower than the bidentate, as a result of stabilizing hydrogen bonding between the non-coordinating benzoate $\mathrm{O}$ atom and adjacent $\mathrm{H}_{2} \mathrm{O}$. However, when entropy changes were included, bidentate coordination was preferred. More recently, de Jong and coworkers calculated structure and frequencies of the $\left[\mathrm{UO}_{2}(\mathrm{OAc})_{3}\right]^{-}$complex [21], in which all the acetate ligands are attached to the uranyl metal center in a bidentate fashion producing a coordination complex of $D_{3 h}$ symmetry. The DFT calculations can provide excellent insight into the prior experimental measurements, yet in general they do not yet account for the highly varied chemical neighborhoods in which the measurements were made, and so comparisons with the condensed phase are frequently difficult to make.

By moving the uranyl complexes into the gas-phase, the influences of neighboring molecules can be mitigated, which can enable a cleaner measurement of the vibrational spectra of uranyl complexes. Charged uranyl coordination complexes can be formed using electrospray-ionization (ESI), which has proven to be a highly versatile means for introducing these species into the gas phase. Recent research by our group [22-26], that of Moulin [27, 28], and Pasilis [29] have demonstrated the great utility of ESI for forming a variety of dioxouranium $\mathrm{V}$ and VI complexes. ESI usually produces multiple species, however, complexes of interest can be isolated on the basis of mass-to-charge 
ratio using selective ion ejection/storage capabilities of a trapped ion mass spectrometer. Once discrete complexes are isolated, infrared spectra can be measured using an action spectroscopy approach in which photon absorption can be monitored by measuring the yield of fragmentation products formed from wavelengthselected infrared multiple photon photodissociation (IRMPD) [30-32]. IRMPD requires deposition of a sufficient number of photons into the uranyl carboxylate complexes to effect photodissociation, and for this, a high-intensity free electron laser that is tunable across the mid-IR is needed. In these studies, the IR photons are provided by a free electron laser (FELIX), which is capable of delivering an intense IR beam to a Fourier transform ion cyclotron resonance mass spectrometer [33-37] that was used to trap and isolate the uranyl carboxylates. This experimental combination has been used to measure IR spectra of discrete metal-ligand complexes [33-35, 38, 39] by recording complex dissociation as a function of wavelength. The IRMPD spectra that are produced usually bear close resemblance to a conventional linear absorption measurement.

Several prior studies of uranyl complexes have shown that quantitative measurements can be made that reflect changes in ligand binding, specifically the effect of the number of ligands, and the relative nucleophilicity of the ligands [40-42], while a later study focused on the influence of formal reduction of the uranyl moiety from the VI oxidation state to $\mathrm{U}(\mathrm{V}) \mathrm{O}_{2}^{+}$[43]. In the present study, we describe the IR spectra of uranyl tris-acetate and tris-benzoate complexes together with complementing DFT studies.

\section{Experimental}

\section{Generation of Nitrate Complexes by ESI}

The complexes studied were generated in a Fourier transform ion cyclotron resonance mass spectrometer that was designed and constructed for use with the free electron laser (see below). The mass spectrometer was equipped with a commercial Z-spray electrospray ionization source (Micromass, Manchester, UK) that produced ions at atmospheric pressure in a spray plume orthogonal to a sampling cone. The operating parameters of the ESI source were very similar to those used in the recent investigations of the tris-nitratouranyl complexes [44]. The solutions used in these experiments were $2 \mathrm{mM}$ uranyl nitrate in water (Aldrich, Milwaukee, WI, USA), diluted 1:1 dilution with methanol, such that the metal concentrations were $\sim 1 \mathrm{mM}$. The solutions were further amended with a few microliters of acetic or benzoic acids, which resulted in formation of the tris-carboxylate anions as a result of their stronger nucleophilicity compared with nitrate. Spray rates were between 10 and $25 \mu \mathrm{L} / \mathrm{min}$.

\section{Fourier Transform Ion Cyclotron Resonance Mass Spectrometry (FT-ICR-MS) [33-35]}

Ions were accumulated in an external hexapole for about $500 \mathrm{~ms}$ before being injected into the ICR cell. Abundant ions corresponding to $\left[\mathrm{UO}_{2}(\mathrm{OAc})_{3}\right]^{-}$or $\left[\mathrm{UO}_{2}(\mathrm{OBz})_{3}\right]^{-}$(where OAc and $\mathrm{OBz}$ represent acetate and benzoate) were formed at $m / z 447$ and 633, respectively, and isolated for IRMPD study using a stored waveform inverse Fourier transform (SWIFT) pulse [45], which ejected all species except those having the desired mass.

\section{Infrared Multiple Photon Dissociation (IRMPD)}

In general, infrared spectra of the tris-carboxylate coordination complexes were collected by monitoring the efficiency of IRMPD as a function of photon energy. In this experiment, isolated ionic complexes were irradiated using two FELIX macropulses (60 mJ per macropulse, $5 \mu$ s pulse duration, bandwidth $0.2 \%-0.5 \%$ of central $\lambda$ ). When the laser frequency matches that of a normal vibrational mode of the gas-phase ion, energy is absorbed and subsequently distributed throughout the ion by intramolecular vibrational redistribution (IVR). The IVR process allows the energy of each photon to be "relaxed" before the absorption of the next, and thus allows promotion of the ion's internal energy to the dissociation threshold by multiple photon absorption [46]. The exact number of photons absorbed by the trapped complexes is not known, but is estimated to be about tens to hundreds, delivered over a $10 \mu$ s time frame. This is long enough for rearrangements to occur, however, prior studies have shown that the infrared spectra obtained using the IRMPD method presented here are comparable to those obtained using linear absorption techniques [35, 39, 44].

To produce infrared spectra, the free electron laser was scanned in 0.01 to $0.04 \mu \mathrm{m}$ increments between 6 and $12.5 \mu \mathrm{m}$, measuring product ions and undissociated precursor ions using the excite/detect sequence of the FT-ICR-MS [47] after each IRMPD step. The IRMPD yield was normalized to the summed fragment ion yield and corrected for variations in FELIX power over the spectral range, then plotted as - $\log$ (1-photofragment yield) versus wavelength.

\section{Molecular Structure, Energetics, and Frequency Calculations using Density Functional Theory}

DFT calculations of structures, energies, and harmonic frequencies for both $\left[\mathrm{UO}_{2}(\mathrm{OAc})_{3}\right]^{-}$and $\left[\mathrm{UO}_{2}(\mathrm{OBz})_{3}\right]^{-}$ were performed with the NWChem [48, 49] software running on the Chinook Supercomputer at the EMSL. No symmetry was applied to the structures during the optimization calculations. The hybrid B3LYP density functional [50] was chosen, and no scaling was applied to the presented frequencies. For uranium, the small core Stuttgart RSC ECP and associated Stuttgart orbital 
basis sets [51-58] were utilized, while Dunning's augmented correlation consistent valence triple zeta (augcc-pvtz) [59] were used for the hydrogen, carbon, and oxygen atoms. In all cases, spherical basis sets were employed.

\section{Results and Discussion}

\section{IRMPD of $\left[\mathrm{UO}_{2}(\mathrm{OAc})_{3}\right]^{-}$}

The negative ESI mass spectrum of the millimolar uranyl nitrate amended with acetic acid produced an abundant ion at $\mathrm{m} / \mathrm{z} 447$ that corresponded to $\left[\mathrm{UO}_{2}(\mathrm{OAc})_{3}\right]^{-}$, the formation of which reflects the stronger affinity of acetate for uranyl compared with nitrate. In addition, lower abundance peaks at $\mathrm{m} / \mathrm{z} 450$ and 453 were seen, which represented substitution of one and two nitrate ligands for the corresponding number of acetates. Isolation of the tris-acetate was accomplished using a SWIFT pulse sequence, which eliminated all other ions from the FT-ICR-MS. IRMPD of the trisacetato complex resulted in elimination of an acetate radical to form $m / z 388$, along with other significant ions at $m / z 346,344$, and 327 that arose from serial fragmentation reactions during IRMPD (Figure 1). The $\mathrm{m} / \mathrm{z} 388$ photofragment was used to generate the IR spectrum (Figure 2).

The IRMPD spectrum is indicative of a structure containing two bidentate ligands, and a single monodentate ligand (the (mono,bis-bi)dentate complex). The conclusion is principally based on the presence of two sets of peaks that are attributable to $\nu_{\text {asym }}$ and $\nu_{\text {sym }}$ stretches in both bidentate and monodentate coordinated acetate. Possibly, there is a contribution from a conformer in which all three acetate ligands are bidentate, as the $\nu_{\text {asym }}$ and $\nu_{\text {sym }}$ peaks from bidentate acetate are at about the same frequency in both conformers. However, if this were the case, then the bidentate stretches would be expected to be more intense (i.e., what would be produced by a linear combination of the spectra in Figure $2 b$ and $c$ ), and this is not the case. Therefore, any contribution from a tris-bidentate conformer is at most minor. The bidentate carboxylate peaks are observed at 1565 and $1450 \mathrm{~cm}^{-1}$ (Figure 2a, Table 1), as suggested by their proximity to the $\nu_{\text {asym }}$ and $\nu_{\text {sym }}$ stretches in the IR spectra of condensed phase acetate-uranyl complexes, and by DFT results (vide

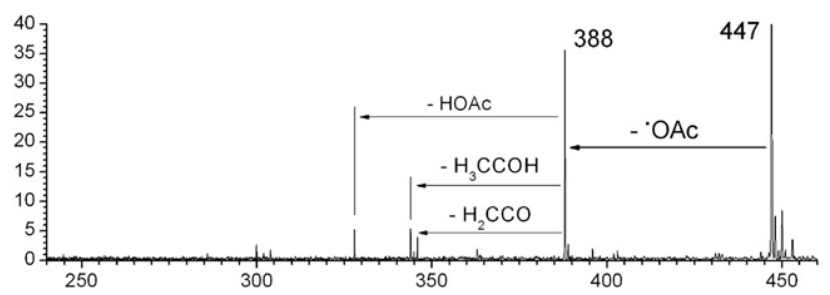

Figure 1. Mass spectrum generated by IRMPD of $\left[\mathrm{UO}_{2}(\mathrm{OAc})_{3}\right]^{-}$ that was isolated and stored in the ICR cell. Photodissociation was carried out by irradiation at $1450 \mathrm{~cm}^{-1}$.

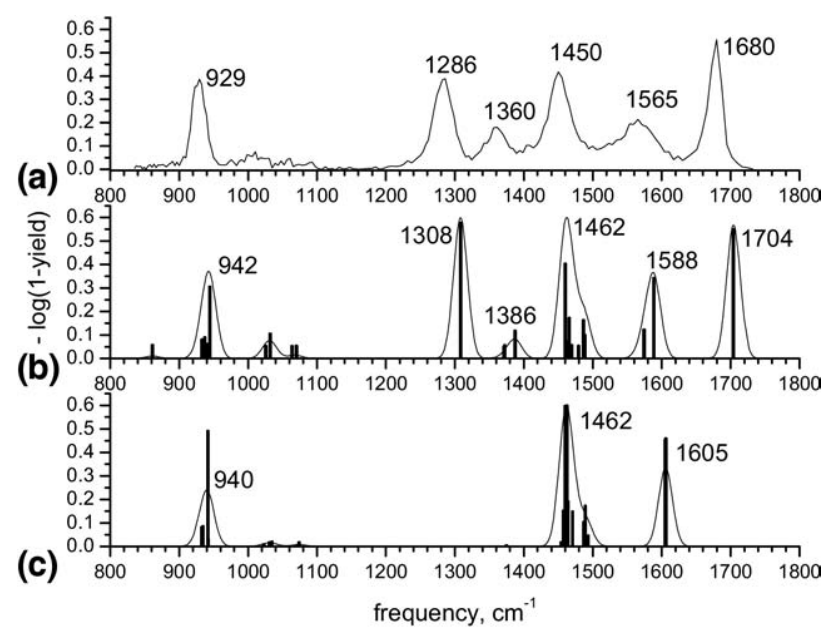

Figure 2. (a) IRMPD of $\left[\mathrm{UO}_{2}(\mathrm{OAc})_{3}\right]^{-}$. (b) DFT-generated spectrum for the mono-,bis-bidentate complex (see Figure 3a). (c) DFT-generated spectrum for the tris-bidentate complex (Figure $3 b)$. Computed harmonic frequencies are unscaled.

infra). Comparing the gas-phase spectrum with prior condensed phase IR frequencies [1-4, 60, 61], the $\nu_{\text {asym }}$ is about $30 \mathrm{~cm}^{-1}$ higher in the gas phase, and the $\nu_{\text {sym }}$ is about $15 \mathrm{~cm}^{-1}$ lower. The $\Delta \nu_{\text {asym-sym }}$ value of $115 \mathrm{~cm}^{-1}$ is

Table 1. Calculated frequencies and mode assignments of the most intense vibrations in the IR spectra of $\left[\mathrm{UO}_{2}(\mathrm{Oac})_{3}\right]^{-}$. A complete listing of calculated frequencies is found in Table 1S

\begin{tabular}{|c|c|c|c|}
\hline \multirow[b]{2}{*}{ IRMPD } & \multicolumn{2}{|l|}{ DFT } & \multirow[b]{2}{*}{ Vibrational mode } \\
\hline & (mono, bis-bi) & tris-bi & \\
\hline 1680 & 1704 & $\mathrm{n} / \mathrm{a}$ & $\begin{array}{l}\text { Monodentate } \mathrm{OAc}, \mathrm{CO}_{2} \\
\text { asymmetric stretch }+\mathrm{HCC} \\
\text { bend }\end{array}$ \\
\hline \multirow[t]{2}{*}{1565} & 1589 & 1606 & $\begin{array}{l}\text { Bidentate } \mathrm{OAc}, \mathrm{CO}_{2} \\
\text { asymmetric stretch }+\mathrm{HCC} \\
\text { bend }\end{array}$ \\
\hline & 1574 & 1605 & $\begin{array}{l}\text { Bidentate } \mathrm{OAc}, \mathrm{CO}_{2} \\
\text { asymmetric stretch }+\mathrm{HCC} \\
\text { bend }\end{array}$ \\
\hline \multirow[t]{4}{*}{1450} & 1488 & 1489 & $\begin{array}{l}\text { Bidentate OAc, C-C stretch }+ \\
\mathrm{CO}_{2} \text { symmetric stretch }+ \\
\mathrm{HCC} \text { bend }\end{array}$ \\
\hline & 1486 & 1487 & $\begin{array}{l}\text { Bidentate OAc, C-C stretch }+ \\
\mathrm{CO}_{2} \text { symmetric stretch }+ \\
\mathrm{HCC} \text { bend }\end{array}$ \\
\hline & 1466 & 1462 & $\begin{array}{l}\text { Bidentate OAc, C-C stretch }+ \\
\mathrm{CO}_{2} \text { symmetric stretch }+ \\
\mathrm{HCC} \text { bend }\end{array}$ \\
\hline & 1460 & 1460 & $\begin{array}{l}\text { Bidentate OAc, } \mathrm{C}-\mathrm{C} \text { stretch }+ \\
\mathrm{CO}_{2} \text { symmetric stretch }+ \\
\mathrm{HCC} \text { bend }\end{array}$ \\
\hline 1360 & 1387 & $\mathrm{n} / \mathrm{a}$ & Bidentate $\mathrm{OAc}, \mathrm{CH}_{3}$ bend \\
\hline 1286 & 1308 & $\mathrm{n} / \mathrm{a}$ & $\begin{array}{l}\text { Monodentate } \mathrm{OAc}, \mathrm{CH}_{3} \\
\text { umbrella and } \mathrm{C}-\mathrm{C} \text { stretch }\end{array}$ \\
\hline 1007 & 1032 & $\mathrm{n} / \mathrm{a}$ & $\begin{array}{c}\text { Bidentate } \mathrm{OAc}, \mathrm{CH}_{3} \text { rock }+ \\
\text { OCO out-of-plane bend }\end{array}$ \\
\hline \multirow[t]{4}{*}{929} & 944 & 942 & $\mathrm{O}=\mathrm{U}=\mathrm{O}$ asymmetric stretch \\
\hline & 941 & 935 & $\mathrm{O}=\mathrm{U}=\mathrm{O}$ asymmetric stretch \\
\hline & 937 & 933 & $\mathrm{O}=\mathrm{U}=\mathrm{O}$ asymmetric stretch \\
\hline & 933 & $\mathrm{n} / \mathrm{a}$ & $\mathrm{O}=\mathrm{U}=\mathrm{O}$ asymmetric stretch \\
\hline
\end{tabular}


55-60 $\mathrm{cm}^{-1}$ greater than that observed for bidentate coordinated acetate in solution [1, 2, 4, 61], suggesting that the ligands are more weakly bound in the gas phase, since the $\Delta \nu_{\text {asym-sym }}$ tends to vary inversely with metal-carboxylate binding strength [13].

The second set of carboxylate stretches are observed at 1680 and $1286 \mathrm{~cm}^{-1}$ and are the $\nu_{\text {asym }}$ and $\nu_{\text {sym }}$ stretches derived from monodentate-coordinated carboxylate, with a large $\Delta \nu_{\text {asym-sym }}$ value of nearly 400 $\mathrm{cm}^{-1}$. A comparison of the frequencies of the analogous stretches measured in the condensed phases for what are thought to be monodentate acetate $[1,2,4,61]$ show that the gas-phase $\nu_{\text {asym }}$ value is blue shifted by about $80 \mathrm{~cm}^{-1}$, while the $\nu_{\text {sym }}$ is red shifted by slightly more than $100 \mathrm{~cm}^{-1}$. Thus, while these frequencies do not closely resemble those assigned to monodentate acetate in the condensed phase, they begin to approach values measured for gas-phase acetic acid [62], in which the proton is not considered to be evenly shared by the oxygen atoms [63].

The other significant peak seen in the IRMPD spectrum is at $929 \mathrm{~cm}^{-1}$, which is the asymmetric uranyl $\nu_{3}$ stretch at a frequency very similar to those recorded in aqueous solution [1, 3, 4]. Values for this frequency have been widely used by our group to evaluate the relative binding of equatorial ligands, both in terms of variable numbers of donor ligands and in terms of ligand nucleophilicity. The value of $929 \mathrm{~cm}^{-1}$ is $20 \mathrm{~cm}^{-1}$ lower than the value measured for the tris-nitratouranyl [44], demonstrating the superior donor ability of the acetate anion compared with nitrate. The tris-acetato $\nu_{3}$ value is also 15 to $20 \mathrm{~cm}^{-1}$ lower than values measured for singly ligated $\mathrm{U}(\mathrm{V}) \mathrm{O}_{2}^{+}$-alcohol complexes [43].

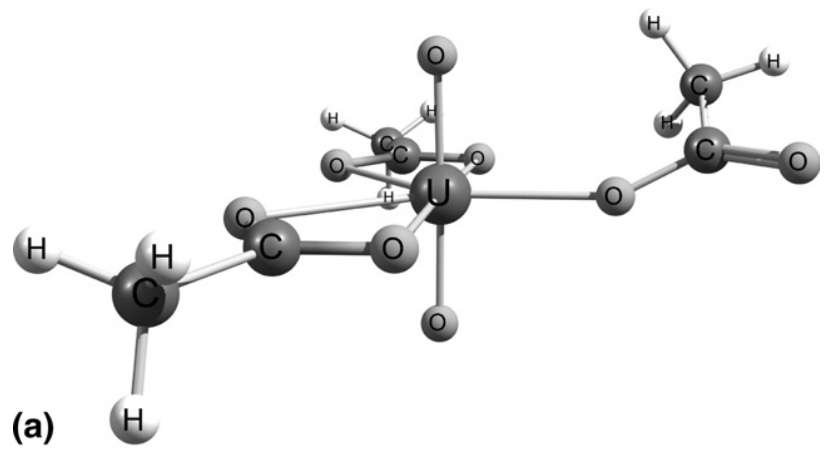

(b)

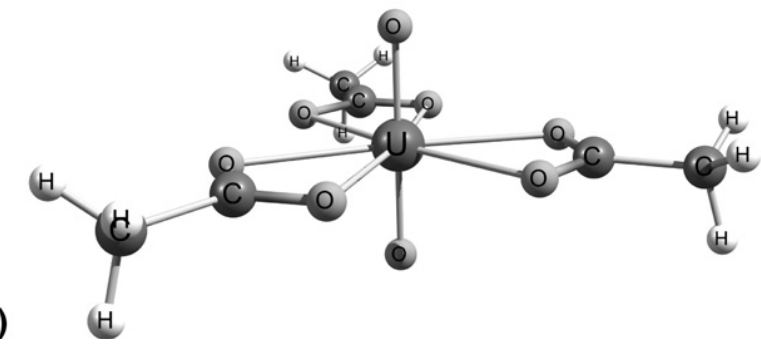

Figure 3. Structures for tris(acetato)uranyl complex calculated using DFT. (a) (mono,bis-bi)-dentate isomer. (b) tris-bidentate isomer.
Table 2. Bond lengths and angles, for calculated (mono-, bis-bi)-dentate, and tris-bidentate OAc conformers. Calculated coordinates are provided in Tables 2 and 3S

\begin{tabular}{lcc}
\hline \multicolumn{1}{c}{ Bond lengths, angles } & $\begin{array}{c}\text { (mono,bis-bi)- } \\
\text { Dentate }\end{array}$ & $\begin{array}{c}\text { tris- } \\
\text { Bidentate }\end{array}$ \\
\hline \hline $\begin{array}{l}\text { U-O } \mathrm{O}_{\text {equatorial, }} \text { monodentate } \\
\text { OAc }\end{array}$ & $2.236 \AA$ & n.a. \\
$\begin{array}{l}\mathrm{U}-\mathrm{O}_{\text {equatorial, }} \text { bidentate } \\
\text { OAc, }\end{array}$ & $2.470-2.500 \AA$ & $2.515 \AA$ \\
$\mathrm{U}-\mathrm{O}_{\text {axial }}$ & $1.781 \AA$ & $1.779 \AA$ \\
I O-U-O & $178.19^{\circ}$ & $179.99^{\circ}$ \\
/ $\mathrm{C}_{\text {bidentate }}-\mathrm{U}-\mathrm{C}_{\text {bidentate }}$ & $130.61^{\circ}$ & $120.00^{\circ}$ \\
I $\mathrm{C}_{\text {bidentate }} \mathrm{U}-\mathrm{O}_{\text {equatorial, }}$ & $110.56^{\circ}, 118.83^{\circ}$ & n.a. \\
monodenate & & \\
\hline
\end{tabular}

The DFT calculations for the tris-acetate complex produced two structures having nearly equivalent energies: a tris-bidentate conformer was a mere $0.5 \mathrm{kcal} /$ mol lower in energy than a (mono,bis-bi)-dentate conformer (see supplementary material, which can be found in the electronic version of this article). The energetic preference notwithstanding, the IR spectrum calculated for the (mono,bis-bi)dentate complex (Figure 3a) was in strong agreement with the IRMPD spectrum. An intense band at $1704 \mathrm{~cm}^{-1}$ that corresponds to the $\nu_{\text {asym }}$ stretch for the monodentate acetate, in good agreement with the measured value of $1680 \mathrm{~cm}^{-1}$. DFT tends to over-predict ligand frequencies, and modest scaling would adjust the monodentate $\nu_{\text {asym }}$ to a slightly lower value, leading to closer agreement with the measurement. The other vibration that is derived from the monodentate acetate ligand is calculated at 1308 $\mathrm{cm}^{-1}$, which correlates with the $\nu_{\text {sym }}$ of the carboxylate group that is strongly coupled with $\mathrm{CH}_{3}$ deformation and $\mathrm{C}-\mathrm{C}$ stretching modes.

DFT peaks calculated at 1588 and $1460 \mathrm{~cm}^{-1}$ for the (mono,bis-bi)dentate complex correspond to the $\nu_{\text {asym }}$ and $\nu_{\text {sym }}$ vibrations of the bidentate acetate ligands, and are just over $20 \mathrm{~cm}^{-1}$ higher than the IRMPD measured values (as in the case of the monodentate acetate). The other two notable stretches in the calculated spectrum are found at $1386 \mathrm{~cm}^{-1}$ and $942 \mathrm{~cm}^{-1}$. The former is derived from the $\mathrm{CH}_{3}$ bend of the monodentate acetate, while the latter is the uranyl $\nu_{3}$. Like the carboxylate stretches, both of these are at slightly higher frequency compared with the IRMPD spectrum.

The IR spectrum calculated for the tris-bidentate conformer (Figure 2c and Figure $3 b$ ) is dissimilar from the spectrum calculated for the (mono,bis-bi)-dentate conformer, and from the IRMPD spectrum, in that it lacks carboxylate stretches derived from monodentate acetate. The spectrum for the tris-bidentate conformer contains strong absorptions at 1605 and $1462 \mathrm{~cm}^{-1}$ that correspond to the $\nu_{\text {asym }}$ and $\nu_{\text {sym }}$ stretches of bidentatecoordinated acetate ligands. Note that the $\Delta \nu_{\text {asym-sym }}$ value of $143 \mathrm{~cm}^{-1}$ is slightly greater than that calculated for the (mono,bis-bi)-dentate conformer, suggesting that overall the strength of bidentate acetate binding is lower in this compound. Even with this being the case, 


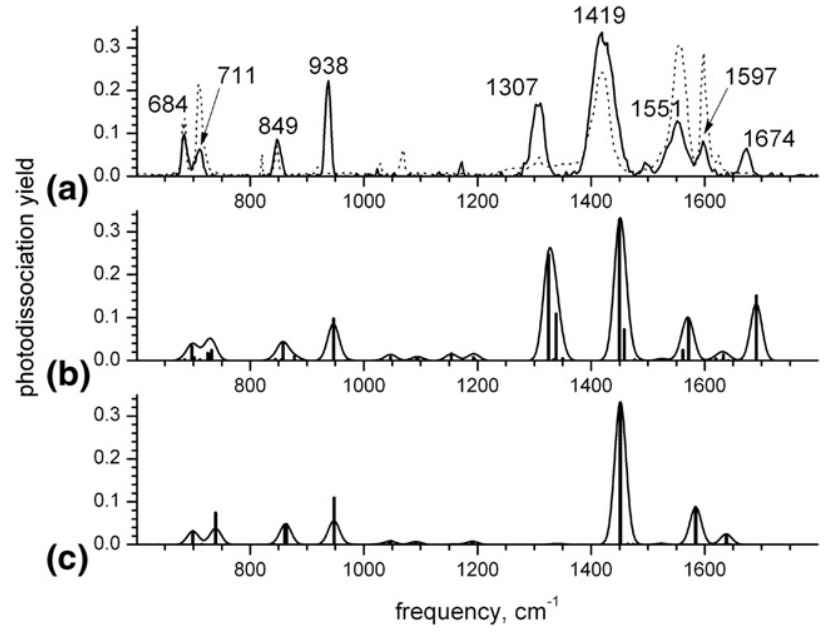

Figure 4. (a) IRMPD of $\left[\mathrm{UO}_{2}(\mathrm{OBz})_{3}\right]^{-}$(solid trace), plotted with the NIST spectrum of NaOBz (dotted trace). (b) DFT-generated spectrum for the (mono-,bis-bi)-dentate complex (see Figure 5a). (c) DFTgenerated spectrum for the tris-bidentate complex (Figure $5 b$ ).

the calculations suggest that the total electron density contributed to the uranium metal center is slightly greater for the tris-bidentate conformer, because the uranyl $\nu_{3}$ at $940 \mathrm{~cm}^{-1}$ is slightly lower in frequency than the corresponding band in the (mono,bis-bi)dentate conformer.

Comparisons of the structural parameters calculated for the two conformers (Table 2) support the conclusions derived from the comparisons of the $\Delta \nu_{\text {asym-sym }}$ and uranyl $\nu_{3}$ values, viz., that the bidentate acetate ligands are slightly more loosely bound in the trisbidentate conformer, and the overall electron density donated to the uranyl molecule is greater. The $\mathrm{U}-\mathrm{O}_{\text {equatorial }}$ bond lengths for the bidentate acetate ligands are slightly shorter in the (mono,bis-bi)-dentate conformer, and the $\mathrm{U}-\mathrm{O}_{\text {axial }}$ bond length is slightly longer. The presence of the monodentate acetate also distorts the overall symmetry of the complex, in that the angle between the two bidentate acetate ligands increases to around $130^{\circ}$, compared with $120^{\circ}$ in the tris-bidentate molecule. The presence of the monodentate $\mathrm{OAc}$ in the (mono,bis-bi)-dentate conformer also distorts the linearity of the uranyl moiety, such that the $\mathrm{O}_{\text {axial }}-\mathrm{U}-\mathrm{O}_{\text {axial }}$ bond angle is decreased to 178.17 from 180.00 in the tris-bidentate conformer. The axial O atoms are pushed away from the monodentate acetate.

\section{IRMPD of $\left[\mathrm{UO}_{2}(\mathrm{OBz})_{3}\right]^{-}$}

IRMPD of $\left[\mathrm{UO}_{2}(\mathrm{OBz})_{3}\right]^{-}$at $\mathrm{m} / \mathrm{z} 533$ generated three salient fragment ions: $\left[\mathrm{UO}_{2}(\mathrm{OBz})_{2}\right]^{-}$at $\mathrm{m} / \mathrm{z} 512$ by elimination of a benzoate radical, $\left[\mathrm{UO}_{2}(\mathrm{OBz})_{2}-\mathrm{H}\right]^{-}$at $\mathrm{m} / \mathrm{z} 511$ by elimination of benzoic acid, and $\left[\mathrm{UO}_{2}(\mathrm{OBz})-\right.$ $\mathrm{H}]^{-}$at $\mathrm{m} / \mathrm{z} 390$ by elimination of the benzoate radical plus benzoic acid. The IRMPD spectrum was generated by summing the intensities of these three dissociation channels to maximize signal-to-noise. We note that two of the three channels are above the dissociation threshold, and inclusion of higher energy channels can produce red shifts in the IRMPD peaks, however, in this case this effect was modest (zero to a few $\mathrm{cm}^{-1}$ ).

The IRMPD spectrum contained multiple bands, which were assigned on the basis of comparisons with the spectrum of sodium benzoate in the NIST database (Figure 4a), and with spectra generated using DFT (Figure $4 \mathrm{~b}$, c, vide infra). The comparison with sodium benzoate [62] and the IRMPD spectrum shows a near perfect agreement with six different peaks corresponding to the $\mathrm{C}=\mathrm{C}$ aromatic stretch at 1597 , the $\nu_{\text {asym }}$ and $\nu_{\text {sym }}$ stretches of the carboxylate at 1551 and 1419, the $\mathrm{CO}_{2}$ bend at 849 , and the out of plane deformations at 711 and $684 \mathrm{~cm}^{-1}$ (Table 3) $[9,11,13]$. The $\nu_{\text {asym }}$ and $\nu_{\text {sym }}$ frequencies measured at $1551 \mathrm{~cm}^{-1}$ and $1419 \mathrm{~cm}^{-1}$ $\left(\Delta \nu_{\text {asym-sym }}=132 \mathrm{~cm}^{-1}\right)$ are assigned as bidentatecoordinated benzoate. These values are very similar to those measured in the spectrum sodium benzoate [11], indicating that the coordinated uranyl is binding with the benzoate ligand to about the same extent as a sodium cation. However, the $\Delta \nu_{\text {asym-sym }}$ for bidentate $\mathrm{OBz}$ in the present uranyl complex not quite as large as values in the spectra of potassium, rubidium, or cesium

Table 3. Calculated frequencies and mode assignments of the most intense vibrations in the spectra of $\left[\mathrm{UO}_{2}(\mathrm{OBz})_{3}\right]^{-}$. A complete listing of calculated frequencies is found in Table $4 \mathrm{~S}$

\begin{tabular}{|c|c|c|c|}
\hline \multirow[b]{2}{*}{ IRMPD } & \multicolumn{2}{|l|}{ DFT } & \multirow[b]{2}{*}{ Vibrational mode } \\
\hline & (mono, bis-bi) & tris-bi & \\
\hline 1674 & 1691 & $\mathrm{n} / \mathrm{a}$ & $\begin{array}{l}\mathrm{V}_{\text {asym, }} \mathrm{CO}_{2} \text { stretch } \\
\text { monodentate } \mathrm{OBz} \text { (non- } \\
\text { bonding } \mathrm{C}=\mathrm{O} \text { ) }\end{array}$ \\
\hline \multirow[t]{2}{*}{1597} & 1633 & 1638 & $\begin{array}{l}\mathrm{C}=\mathrm{C} \text { stretches and } \\
\text { bidentate } \mathrm{O}-\mathrm{C}-\mathrm{O} \\
\text { asymmetric stretch }\end{array}$ \\
\hline & & 1637 & $\mathrm{C}=\mathrm{C}$ stretches benzene ring \\
\hline \multirow[t]{2}{*}{1551} & 1572 & 1584 & $\begin{array}{l}\mathrm{V}_{\text {asym }}, \mathrm{CO}_{2} \text { stretch bidentate } \\
\mathrm{OBz}\end{array}$ \\
\hline & 1562 & 1584 & $\begin{array}{l}\mathrm{V}_{\text {asym, }} \mathrm{CO}_{2} \text { stretch bidentate } \\
\mathrm{OBz}\end{array}$ \\
\hline \multirow[t]{2}{*}{1419} & 1458 & 1452 & $\begin{array}{l}\mathrm{V}_{\text {sym }}, \mathrm{CO}_{2} \text { stretch bidentate } \\
\mathrm{OBz}\end{array}$ \\
\hline & 1450 & 1451 & $\begin{array}{l}\mathrm{V}_{\text {sym }}, \mathrm{CO}_{2} \text { stretch bidentate } \\
\mathrm{OBz}\end{array}$ \\
\hline \multirow[t]{2}{*}{1307} & 1339 & $n / a$ & $\begin{array}{l}\mathrm{V}_{\text {sym }} \text { stretch of bonding } \mathrm{CO} \\
\text { on monodentate } \mathrm{OBz}\end{array}$ \\
\hline & 1325 & & $\begin{array}{l}\mathrm{V}_{\text {sym }} \text { stretch of bonding } \mathrm{CO} \\
\text { on monodentate } \mathrm{OBz}\end{array}$ \\
\hline 938 & 947 & 948 & $\mathrm{~V}_{3}, \mathrm{UO}_{2}$ asymmetric stretch \\
\hline 849 & 858 & 864 & $\begin{array}{l}\mathrm{CO}_{2} \text { bend coupled with } \mathrm{UO}_{2} \\
\text { symmetric stretch }\end{array}$ \\
\hline \multirow[t]{3}{*}{711} & 732 & 739 & $\begin{array}{l}\mathrm{CO}_{2} \text { and } \mathrm{CH} \text { out of plane } \\
\text { bend }\end{array}$ \\
\hline & 731 & & $\begin{array}{l}\mathrm{CH} \text { and } \mathrm{CO}_{2} \text { out of plane } \\
\text { bend }\end{array}$ \\
\hline & 725 & & $\begin{array}{l}\mathrm{CO}_{2} \text { bend (bidentate } \mathrm{OBz} \text { ) } \\
\text { and } \mathrm{CH} \text { in plane bend }\end{array}$ \\
\hline 684 & 697 & 699 & $\begin{array}{l}\mathrm{CO}_{2} \text { symmetric or out of } \\
\text { plane deformation }\end{array}$ \\
\hline
\end{tabular}


(a)

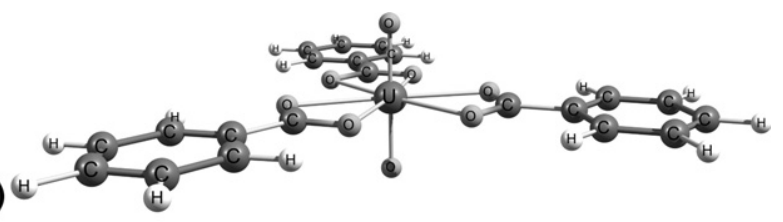

(b)

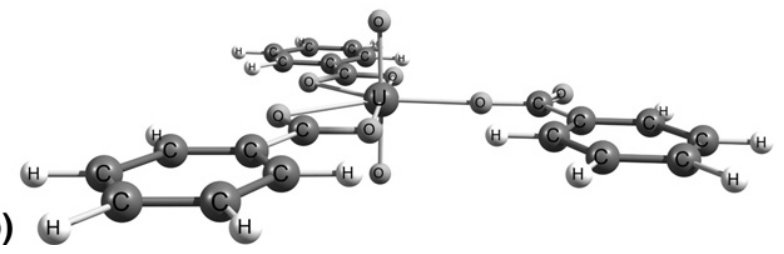

Figure 5. Structures of $\left[\mathrm{UO}_{2}(\mathrm{OBz})_{3}\right]^{-}$complexes. (a), (mono, bis-bi)-dentate conformer. (b), tris-bidentate conformer.

[13]: the general trend noted is that as the coordinated cation becomes softer, the $\Delta \nu_{\text {asym-sym }}$ value becomes larger. Based on the values measured for the monodentate carboxylates in this study, this suggests that coordination becomes more monodentate-like as the cation binding becomes softer.

The peaks at 1674 and $1307 \mathrm{~cm}^{-1}$ assigned to monodentate-coordinated benzoate: note that the $\nu_{\text {asym }}$ and $\nu_{\text {sym }}$ values are similar to those seen for the monodentate acetate (vide supra), and that the $\Delta \nu_{\text {asym-sym }}$ $\left(367 \mathrm{~cm}^{-1}\right)$ is also similar. It is informative to compare the measured $\nu_{\text {asym }}$ and $\nu_{\text {sym }}$ frequencies with those measured for gas-phase, non-complexed benzoate [64], and benzoic acid [62]. The $\nu_{\text {asym }}, \nu_{\text {sym }}$, and $\Delta v_{\text {asym-sym }}$ values are $1624 \mathrm{~cm}^{-1}, 1309 \mathrm{~cm}^{-1}$, and $315 \mathrm{~cm}^{-1}$, (respectively) for non-complexed benzoate, and $1770 \mathrm{~cm}^{-1}$, $1353 \mathrm{~cm}^{-1}$, and $417 \mathrm{~cm}^{-1}$ for benzoic acid. The measured values for the monodentate-coordinated uranyl benzoate are intermediate between these two benchmark values, indicating significantly more free $\mathrm{C}=\mathrm{O}$ character than in the non-coordinated benzoate, but not as much as in benzoic acid.

The asymmetric uranyl stretch is measured at 939 $\mathrm{cm}^{-1}$, a value slightly higher than that for the trisacetatouranyl complex $\left(\nu_{3}=929 \mathrm{~cm}^{-1}\right)$. This indicates that the benzoate is bound slightly less tightly compared with the acetate, which is consistent with the facts that benzoic acid is a stronger acid than acetic acid, and that benzoate is a weaker nucleophile than is acetate. Benzoate is a stronger nucleophile than is nitrate, as reflected by the fact that the $\nu_{3}$ for the tris-benzoate is less than that for the tris-nitrate complex $\left(\nu_{3}=949\right.$ $\mathrm{cm}^{-1}$ ) [44].

The IR spectra generated by DFT are in good agreement with the conclusion that the gas-phase $\left[\mathrm{UO}_{2}(\mathrm{OBz})_{3}\right]^{-}$complex has a (mono,bis-bi)-dentate structure. All nine of the salient peaks are reproduced by the calculations (Figure $4 b$ ), albeit at higher frequency by $\sim 15$ to $40 \mathrm{~cm}^{-1}$ (as in the case of the tris-acetato complex). This is not unexpected as no scaling has been applied to the computed harmonic frequencies. The contributions made by the monodentatecoordinated benzoate are highlighted by a comparison of the spectra calculated for (mono,bis-bi)-dentate and tris-bidentate conformers (Figure $4 \mathrm{~b}, \mathrm{c}$ ). The two spectra are nearly identical, with the glaring exception of peaks at 1691 and $1325-1329 \mathrm{~cm}^{-1}$ that are not present in the tris-bidentate spectrum. Interestingly, the zero point corrected energy of the (mono,bis-bi)-dentate conformer is $1.6 \mathrm{kcal} / \mathrm{mol}$ higher than the tris-bidentate version. Possibly, a fraction of the population consists of the tris-bidentate conformer, which in fact is suggested by the fact that the $\nu_{\text {sym }}$ peak for the bidentate benzoate is a bit more intense in the IRMPD spectrum than predicted by the IRMPD spectrum of the (mono, bis-bi)-dentate conformer. A more intense bidentate $\nu_{\text {sym }}$ peak would be expected by a combination of the spectra calculated for the (mono,bis-bi)-, and trisbidentate conformers (a combination of spectra in Figure $4 b, c)$.

The structure calculated for the tris-bidentate $\left[\mathrm{UO}_{2}(\mathrm{OBz})_{3}\right]^{-}$is nearly perfectly $\mathrm{D}_{3 \mathrm{~h}}$, with C-U-C and $\mathrm{O}=\mathrm{U}=\mathrm{O}$ bond angles very close to $120^{\circ}$ and $180^{\circ}$, respectively, and the $\mathrm{U}-\mathrm{O}_{\text {equatorial }}$ bond distances at about $2.442 \AA$ (Figure 5, Table 4). The latter value is in excellent accord with what would be expected for bidentate coordination based on EXAFS measurements [17]. When one of the $\mathrm{OBz}$ ligands is converted to a monodentate conformation, the symmetry is distorted, with the C-U-C angle involving the two bidentate $\mathrm{OBz}$ ligands increasing to $\sim 128^{\circ}$, and the $\mathrm{O}-\mathrm{U}-\mathrm{O}$ bond angle decreasing to $\sim 177.94^{\circ}$, bent away from the monodentate benzoate. The $\mathrm{U}_{-} \mathrm{O}_{\text {equatorial }}$ distance for the monodentate $\mathrm{OBz}$ is much shorter, at $2.240 \AA$, while the $\mathrm{U}-\mathrm{O}_{\text {equatorial }}$ distances for the bidentate benzoates were considerably lengthened. The $\mathrm{U}-\mathrm{O}_{\text {axial }}$ bond distance was shorter in the (mono,bis-bi) conformer, indicating

Table 4. Bond lengths and angles, for calculated (mono-, bis-bi)-dentate, and tris-bidentate OBz conformers. Complete sets of coordinates for both conformers are found in Tables S5 and S6

\begin{tabular}{|c|c|c|}
\hline Bond lengths, angles & (mono,bis-bi)-Dentate & tris-Bidentate \\
\hline $\begin{array}{l}\mathrm{U}-\mathrm{O}_{\text {equatorial, }} \text { monodentate } \mathrm{OBz} \\
\mathrm{U}-\mathrm{O}_{\text {equatorial, }} \text { bidentate } \mathrm{OBz} \\
\mathrm{U}-\mathrm{O}_{\text {axial }} \\
\text { / O-U-O } \\
\text { / } \mathrm{C}_{\text {bidentate }}-\mathrm{U}-\mathrm{C}_{\text {bidentate }} \\
\text { / } \mathrm{C}_{\text {bidentate }}-\mathrm{U}-\mathrm{O}_{\text {equatorial, monodenate }}\end{array}$ & $\begin{array}{c}2.240 \AA \\
2.469,2.503,2.505,2.501 \AA \\
1.777 \AA \\
177.94^{\circ} \\
129.98^{\circ} \\
111.84^{\circ}, 118.17^{\circ}\end{array}$ & $\begin{array}{c}\text { n.a. } \\
2.442 \AA \\
1.787 \AA \\
179.98^{\circ} \\
119.98^{\circ}, 120.06^{\circ}, 119.96^{\circ} \\
\text { n.a. }\end{array}$ \\
\hline
\end{tabular}


that less electron density is donated to the uranium metal center than in the tris-bidentate version.

\section{Conclusions}

The coordination of carboxylate ligands to the metal center in the uranyl molecule has been a subject of ongoing study for more than a half century. The overall conclusion is that in the condensed phases, either bidentate or monodentate carboxylate coordination is possible, depending on the chemical environment and associated nearest chemical neighbors. Moving trisacetato and -benzoato complexes into the gas phase eliminates influences from solvent or crystal structure, and results in conformers in which two carboxylates are bidentate, and one is monodentate. The conclusion is based on infrared spectra in which two sets $\nu_{\text {asym }}$ and $\nu_{\text {sym }}$ carboxylate stretching frequencies are recorded, one corresponding to bidentate carboxylate, and the other to monodentate. The (mono,bis-bi)-dentate conformers are clearly preferred to the tris-bidentate versions despite the fact that the DFT calculations indicate that energetically the two conformers are practically indistinguishable (for both the acetate and benzoate complexes).

\section{Acknowledgments}

G.S.G. was supported by the U.S. Department of Energy, Assistant Secretary for Environmental Management, and the INL Laboratory Directed Research and Development Program under DOE Idaho Operations Office Contract DE-AC07-05ID14517. M.J.vS. was supported in part through a grant from the U.S. National Science Foundation (NSF grant CAREER-0239800). J.O. is supported by the Nederlandse Organisatie voor Wetenschappelijk Onderzoek (NWO). The authors gratefully acknowledge the skillful assistance by the FELIX staff, in particular Dr. B. Redlich. Construction and shipping of the FT-ICR-MS instrument was made possible through funding from the National High Field FT-ICR Facility (grant CHE-9909502) at the National High Magnetic Field Laboratory, Tallahassee, FL. The research of W.A.dJ. was supported by the BES Heavy Element Chemistry program of the U.S. Department of Energy, Office of Science, and was performed in part using the Molecular Science Computing Facility in the William R. Wiley Environmental Molecular Sciences Laboratory, a national scientific user facility sponsored by the U.S. Department of Energy's Office of Biological and Environmental Research located at the Pacific Northwest National Laboratory, which is operated for the Department of Energy by Battelle. References herein to any specific commercial product, process, or service by trade name, manufacturer, or otherwise, does not necessarily constitute or imply its endorsement, recommendation, or favoring by the U.S. Government, any agency thereof, or any company affiliated with the Idaho National Laboratory.

\section{Appendix A Supplementary Material}

Supplementary material associated with this article may be found in the online version at doi:10.1016/ j.jasms.2010.01.021.

\section{References}

1. Gal, M.; Goggin, P. L.; Mink, J. Mid-, Far-Infrared and Raman Spectra of Uranyl Complexes in Aqueous Solutions. J. Mol. Struct. 1984, 114, $459-462$.

2. Gal, M.; Goggin, P. L.; Mink, J. Vibrational Spectroscopic Studies of Uranyl Solutions in Aqueous and Nonaqueous Solutions. Spectrochim. Acta 1992, 48A, 121-132.

3. Kakihana, M.; Nagumo, T.; Okamoto, M.; Kakihana, H. Coordination Structures for Uranyl Carboxylate Complexes in Aqueous Solution Studied by IR and ${ }^{13} \mathrm{C}$ NMR Spectra. J. Phys. Chem. 1987, 91, 6128-6136.

4. Quiles, F.; Burneau, A. Infrared and Raman Spectroscopic Study of Uranyl Complexes: Hydroxide and Acetate Derivatives in Aqueous Solution. Vibrat. Spectrosc. 1998, 18, 61-75.

5. Jones, L. H. Infrared Spectra and Structure of the Crystalline Sodium Acetate Complexes of U(VI), Np(VI), Pu(VI), and Am(VI). A Comparison of Metal-Oxygen Bond Distance and Bond Force Constant in This Series. J. Chem. Phys. 1955, 23, 2105-2107.

6. Templeton, D. H.; Zalkin, A.; Ruben, H.; Templeton, L. K. Redetermination and Absolute Configuration of Sodium Uranyl(VI) Triacetate. Acta Crystallogr. B 1985, C41, 1439-1441.

7. Howatson, D. M.; Grev, D. M.; Morosin, B. Crystal and Molecular Structure of Uranyl Acetate Dihydrate. J. Inorg. Nucl. Chem. 1975, 37, 1933-1935.

8. Nguyen-Trung, C.; Begun, G. M.; Palmer, D. A. Aqueous Uranium Complexes. 2. Raman-Spectroscopic Study of the Complex-Formation of the Dioxouranium(VI) Ion with a Variety of Inorganic and Organic Ligands. Inorg. Chem. 1992, 31, 5280-5287.

9. Chapman, D.; Lloyd, D. R.; Prince, R. H. Hydrogen Bonding in Aqueous Solutions of Some Dicarboxylic Acids. J. Chem. Soc. 1964, 550-555.

10. Dunn, G. E.; McDonald, R. S. Infrared Spectra of Aqueous Sodium Benzoate and Salicylates in the Carboxyl-Stretching Region: Chelation in Aqueous Sodium Salicylates. Can. J. Chem. 1969, 47, 4577-4588.

11. Davies, M.; Jones, R. L. Infrared Absorptions and Molecular Structures of Phenol, Phenolphthalein, Fluorescein, and Some Alkali Derivatives. J. Chem. Soc. 1954, 120-125.

12. Stimson, M. M. Sodium and Potassium Cation Dependence of the Infrared Absorption of $\mathrm{COO}^{-}$. J. Chem. Phys. 1954, 22, 1942.

13. Green, J. H. S.; Kynaston, W.; Lindsey, A. S. The Vibrational Spectra of Benzene Derivatives. I. Nitrobenzene, the Benzoate Ion, Alkali Metal Benzoates, and Salicylates. Spectrochim. Acta 1961, 17, 486-502.

14. Den Auwer, C.; Simoni, E.; Conradson, S.; Madic, C. Investigating Actinyl Oxo Cations by X-ray Absorption Spectroscopy. Eur. J. Inorg. Chem. 2003, 3843-3859.

15. Jiang, J.; Rao, L.; Di Bernardo, P.; Zanonato, P. L.; Bismondo, A. Complexation of Uranium(VI) with Acetate at Variable Temperatures. J. Chem. Soc. Dalton Trans. 2002, 1832-1838.

16. Denecke, M. A.; Reich, T.; Bubner, M.; Pompe, S.; Heise, K. H.; Nitsche, H.; Allen, P. G.; Bucher, J. J.; Edelstein, N. M.; Shuh, D. K. Determination of Structural Parameters of Uranyl Ions Complexed with Organic Ccids Using EXAFS. J. Alloys Comp. 1998, 271/273, 123-127.

17. Reich, T.; Hudson, E. A.; Denecke, M. A.; Allen, P. G.; Nitsche, H. Structural Analysis of Uranium(VI) Complexes by X-ray Absorption Spectroscopy. Surf. Investig. 1998, 13, 557-568.

18. Denecke, M. A.; Reich, T.; Pompe, S.; Bubner, M.; Heise, K. H.; Nitsche, H.; Allen, P. G.; Bucher, J. J.; Edelstein, N. M.; Shuh, D. K.; Czerwinski, K. R. EXAFS. Investigations of the Interaction of Humic Acids and Model Compounds with Uranyl Cations in Solid Complexes. Radiochim. Acta 1998, 82, 103-108.

19. Zalkin, A.; Ruben, H.; Templeton, D. H. Structure of Nickel Uranyl Acetate Hexahydrate. Acta Crystallogr. B 1982, 38, 610-612.

20. Ray, R. S.; Kruger, S.; Rosch, N. Uranyl Monocarboxylates of Aromatic Acids: A Density Functional Model Study of Uranyl Humate Complexation. Dalton Trans. 2009, 3590-3598.

21. de Jong, W. A.; Apra, E.; Windus, T. L.; Nichols, J. A.; Harrison, R. J.; Gutowski, K. E.; Dixon, D. A. Complexation of the Carbonate, Nitrate, and Acetate Anions with the Uranyl Dication: Density Functional Studies with Relativistic Effective Core Potentials. J. Phys. Chem. A 2005, 109, 11568-11577.

22. Chien, W.; Anbalagan, V.; Zandler, M.; Hanna, D.; Van Stipdonk, M.; Gresham, G.; Groenewold, G. Intrinsic Hydration of Monopositive Uranyl-Hydroxide, -Nitrate, and -Acetate Cations. J. Am. Soc. Mass Spectrom. 2004, 15, 777-783.

23. Groenewold, G. S.; Van Stipdonk, M. J.; Gresham, G. L.; Chien, W.; Bulleigh, K.; Howard, A. Collision-Induced Dissociation Tandem Mass Spectrometry of Desferrioxamine Siderophore Complexes from Eectrospray Ionization of $\mathrm{UO}_{2}{ }^{2+}, \mathrm{Fe}^{3+}, \mathrm{Ca}^{2+}$ Solutions. J. Mass Spectrom. 2004, 39, 752-761.

24. Van Stipdonk, M. J.; Chien, W.; Anbalagan, V.; Gresham, G. L.; Groenewold, G. S. Oxidation Of 2-Propanol Ligands Following Collision-Induced Dissociation Of A Gas-Phase Uranyl Complex. Int. J. Mass Spectrom. 2004, 237, 175-183.

25. Van Stipdonk, M. J.; Chien, W.; Angalaban, V.; Bulleigh, K.; Hanna, D. Groenewold, G. S. Gas-Phase Complexes Containing The Uranyl Ion and Acetone. J. Phys. Chem. A 2004, 108, 10448-10457.

26. Van Stipdonk, M. J.; Chien, W.; Bulleigh, K.; Wu, Q.; Groenewold, G. S. Gas-Phase Uranyl-Nitrile Complex Ions. J. Phys. Chem. A 2006, 110, 959-970. 
27. Moulin, C.; Charron, N.; Plancque, G.; Virelizier, H. Speciation of Uranium by Electrospray Ionization Mass Spectrometry: Comparison with Time-Resolved Laser-Induced Fluorescence. Appl. Spectrosc. 2000, $54,843-848$

28. Moulin, V.; Moulin, C. Radionuclide Speciation in the Environment: A Review. Radiochim. Acta 2001, 89, 773-778.

29. Pasilis, S.; Somogyi, A.; Herrmann, K.; Pemberton, J. E. Ions Generated from Uranyl Nitrate Solutions by Electrospray Ionization (ESI) and Detected with Fourier Transform Ion-Cyclotron Resonance (FT-ICR) Mass Spectrometry. J. Am. Soc. Mass Spectrom. 2006, 17, 230-240.

30. Duncan, M. A. Spectroscopy of Metal ICon complexes: Gas-Phase Models for Solvation. Annu. Rev. Phys. Chem. 1997, 48, 69-93.

31. Duncan, M. A. Infrared Spectroscopy to Probe Structure and Dynamics in Metal Ion-Molecule cComplexes. Int. Rev. Phys. Chem. 2003, 22, 407-435.

32. Lemaire, J.; Boissel, P.; Heninger, M.; Mauclaire, G.; Bellec, G.; Mestdagh, H.; Simon, A.; Le Caer, S.; Ortega, J. M.; Glotin, F.; Maitre, P. Gas Phase Infrared Spectroscopy of Selectively Prepared Ions. Phys. Rev. Lett. 2002, 89, 273002-1-273002-4.

33. Moore, D. T.; Oomens, J.; Eyler, J. R.; Meijer, G.; von Helden, G.; Ridge, D. P. Gas Phase IR Spectroscopy of Anionic Iron Carbonyl Clusters. J. Am. Chem. Soc. 2004, 126, 14726-14727.

34. Moore, D. T.; Oomens, J.; van der Meer, L.; von Helden, G.; Meijer, G.; Valle, J.; Marshall, A. G.; Eyler, J. R. Probing the Vibrations of Shared $\mathrm{OH}^{+} \mathrm{O}-$ Bound Protons in the Gas Phase. Chem. Phys. Chem. 2004, 5, $740-743$.

35. Oomens, J.; Moore, D. T.; von Helden, G.; Meijer, G.; Dunbar, R. C. The Site of $\mathrm{Cr}^{+}$Attachment to Gas-Phase Aniline from Infrared Spectroscopy. J. Am. Chem. Soc. 2004, 126, 724-725.

36. Valle, J. J.; Eyler, J. R.; Oomens, J.; Moore, D. T.; van der Meer, A. F. G.; von Helden, G.; Meijer, G.; Hendrickson, C. L.; Marshall, A. G.; Blakney, G. T. Free Electron Laser-Fourier Transform Ion Cyclotron Resonance Mass Spectrometry Facility for Obtaining Infrared Multiphoton Dissociation Spectra of Gaseous Ions. Rev. Sci. Instrum. 2005, 76, 023103.

37. Dunbar, R. C.; Moore, D. T.; Oomens, J. IR Spectroscopic Characterization of Intermediates in a Gas-Phase Ionic Reaction: The Decarbonylation of $\mathrm{Co}^{+}$(Acetophenone). Int. J. Mass Spectrom. 2007, 265, 182-186.

38. van Heijnsbergen, D.; Demyk, K.; Duncan, M. A.; Meijer, G.; von Helden, G. Structure Determination of Gas Phase Aluminum Oxide Clusters. Phys. Chem., Chem. Phys. 2003, 5, 2515-2519.

39. Oomens, J.; Tielens, A. G. G. M.; Sartakov, B. G.; Von Helden, G.; Meijer, G. Laboratory Infrared Spectroscopy of Cationic Polycyclic Aromatic Hydrocarbon Molecules. Astrophys. J 2003, 591, 968-985.

40. Groenewold, G. S.; Gianotto, A. K.; Cossel, K. C.; Van Stipdonk, M. J.; Moore, D. T.; Polfer, N.; Oomens, J.; de Jong, W. A.; Visscher, L. Vibrational Spectroscopy of Mass Selected $\left[\mathrm{UO}_{2}(\text { Ligand) }]^{2+} \mathrm{Com}-\right.$ plexes in the Gas Phase: Comparison with Theory. J. Am. Chem. Soc. 2006, 107, 4802-4813.

41. Groenewold, G. S.; Gianotto, A. K.; Cossel, K. C.; Van Stipdonk, M. J.; Oomens, J.; Polfer, N.; Moore, D. T.; de Jong, W. A.; Mcllwain, M. E. Mid-Infrared Vibrational Spectra of Gas-Phase, Acetone-Ligated Cerium Hydroxide Cation. Phys. Chem., Chem. Phys. 2007, 9, 596-606.

42. Groenewold, G. S.; Gianotto, A. K.; Mcllwain, M. E.; Van Stipdonk, M. J.; Kullman, M.; Moore, D. T.; Polfer, N.; Oomens, J.; Infante, I.; Visscher, L.; Siboulet, B.; De Jong, W. A. Infrared Spectroscopy of Discrete Uranyl Anion Complexes. J. Phys. Chem. A 2008, 112, 508-521.

43. Groenewold, G. S.; van Stipdonk, M. J.; de Jong, W. A.; Oomens, J.; Gresham, G. L.; McIlwain, M. E.; Gao, D.; Siboulet, B.; Visscher, L.; Kullman, M.; Polfer, N. Infrared Spectroscopy of Dioxouranium(V) Complexes with Solvent Molecules: Effect of Reduction. Chem. Phys. Chem. 2008, 9, 1278-1285.

44. Groenewold, G. S.; Oomens, J.; de Jong, W. A.; Gresham, G. L.; McIlwain, M. E.; Van Stipdonk, M. J. Vibrational Spectroscopy of Anionic Nitrate Complexes of $\mathrm{UO}_{2}^{2+}$ and $\mathrm{Eu}^{3+}$ Isolated in the Gas Phase. Phys. Chem., Chem. Phys. 2008, 10, 1192-1202.

45. Marshall, A. G.; Wang, T.-C. L.; Ricca, T. L. Tailored Excitation for Fourier Transform Ion Cyclotron Resonance Mass Spectrometry. J. Am. Chem. Soc. 1985, 107, 7893-7897.
46. Bagratashvili, V. N.; Letokov, V. S.; Makarov, A. A.; Ryabov, E. A Multiple Photon Infrared Laser Photophysics and Photochemistry; Harwood: Chur, Switzerland, 1985.

47. Marshall, A. G.; Hendrickson, C. L.; Jackson, G. S. Fourier Transform Ion Cyclotron Resonance Mass Spectrometry: A Primer. Mass Spectrom. Rev. 1998, 17, 1-35.

48. Aprà, E.; Windus, T. L.; Straatsma, T. P.; Bylaska, E. J.; de Jong, W.; Hirata, S.; Valiev, M.; Hackler, M.; Pollack, L.; Kowalski, K.; Harrison, R.; Dupuis, M.; Smith, D. M. A.; Nieplocha, J.; Tipparaju, V.; Krishnan, M.; Auer, A. A.; Brown, E.; Cisneros, G.; Fann, G.; Fruchtl, H.; Garza, J.; Hirao, K.; Kendall, R.; Nichols, J.; Tsemekhman, K.; Wolinski, K.; Anchell, J.; Bernholdt, D.; Borowski, P.; Clark, T.; Clerc, D.; Dachsel, H.; Deegan, M.; Dyall, K.; Elwood, D.; Glendening, E.; Gutowski, M.; Hess, A.; Jaffe, J.; Johnson, B.; Ju, J.; Kobayashi, R.; Kutteh, R.; Lin, Z.; Littlefield, R.; Long, X.; Meng, B.; Nakajima, T.; Niu, S.; Rosing, M. Sandrone, G.; Stave, M.; Taylor, H.; Thomas, G.; van Lenthe, J.; Wong, A.; Zhang, Z. NWChem, A Computational Chemistry Package for Parallel Computers, Version 4.7, Pacific Northwest National Laboratory: Richland, Washington 99352-0999, USA, 2005.

49. Kendall, R. A.; Apra, E.; Bernholdt, D. E.; Bylaska, E. J.; Dupuis, M.; Fann, G. I.; Harrison, R. J.; Ju, J.; Nichols, J. A.; Nieplocha, J.; Straatsma T. P.; Windus, T. L.; Wong, A. T. High Performance Computationa Chemistry: An Overview of NWChem a Distributed Parallel Application. Computer Phys. Commun. 2000, 128, 260-283.

50. Becke, A. D. Density-Functional Thermochemistry. 3. The Role of Exact Exchange. J. Chem. Phys. 1993, 98, 5648-5652.

51. Bergner, A.; Dolg, M.; Kuchle, W.; Stoll, H.; Preuss, H. Ab-Initio Energy-Adjusted Pseudopotentials for Elements of Groups 13-17. Mol. Phys. 1993, 80, 1431-1441.

52. Dolg, M.; Stoll, H.; Preuss, H.; Pitzer, R. M. Relativistic and Correlation Effects for Element 105 (Hahnium, Ha)—a Comparative-Study of M and Mo $(\mathrm{M}=\mathrm{Nb}$, Ta, Ha) Using Energy-Adjusted Ab Initio Pseudopotentials. J. Phys. Chem. 1993, 97, 5852-5859.

53. Fuentealba, P.; Preuss, H.; Stoll, H.; Vonszentpaly, L. A Proper Account of Core-Polarization with Pseudopotentials-Single Valence-Electron Alkali Compounds. Chem. Phys. Lett. 1982, 89, 418-422.

54. Fuentealba, P.; Vonszentpaly, L.; Preuss, H.; Stoll, H. Pseudopotential Calculations for Alkaline-Earth Atoms. J. Phys. B At. Mol. Opt. Phys 1985, 18, 1287-1296.

55. Igel-Mann, G.; Stoll, H.; Preuss, H. Pseudopotentials for Main Group Elements (IIIa through VIIa). Mol. Phys. 1988, 65, 1321-1328.

56. Kaupp, M.; Schleyer, P. V.; Stoll, H.; Preuss, H. Pseudopotential Approaches to $\mathrm{Ca}$, Sr, and Ba Hydrides-Why Are Some Alkaline-Earth Mx2 Compounds Bent. J. Chem. Phys. 1991, 94, 1360-1366.

57. Kuchle, W.; Dolg, M.; Stoll, H.; Preuss, H. Ab Initio Pseudopotentials for $\mathrm{Hg}$ through Rn. 1. Parameter Sets and Atomic Calculations. Mol. Phys. 1991, 74, 1245-1263.

58. Kuchle, W.; Dolg, M.; Stoll, H.; Preuss, H. Energy-Adjusted Pseudopotentials for the Actinides-Parameter Sets and Test Calculations for Thorium and Thorium Monoxide. J. Chem. Phys. 1994, 100, 7535-7542.

59. Dunning, T. H. Gaussian-Basis Sets for Use in Correlated Molecular Calculations. 1. The Atoms Boron through Neon and Hydrogen. J. Chem. Phys. 1989, 90, 1007-1023.

60. Alcock, N. W.; Tracy, V. M.; Weddington, T. C. Acetates and AcetatoComplexes. Part 2. Spectroscopic Studies. J. Chem. Soc. Dalton Trans. 1975, 2243-2249.

61. Quiles, F.; Burneau, A. Infrared and Raman Spectra of Uranyl(VI) Oxo-Hydroxo Complexes in Acid Aqueous Solutions: A Chemometric Study. Vibrat. Spectrosc. 2000, 23, 231-241.

62. Lias, S. G. NIST Chemistry WebBook, http://webbook.nist.gov/. United States Department of Commerce, National Institute of Standards and Technology: Washington, D.C., 2003.

63. Jeffrey, G. A. An Introduction to Hydrogen Bonding; Oxford University Press: New York, 1997, pp 11-50.

64. Oomens, J.; Steill, J. D. Free Carboxylate Stretching Modes. J. Phys. Chem. A 2008, 112, 3281-3283. 